\title{
Radical Cystectomy in the Elderly: National Trends and Disparities in Perioperative Outcomes and Quality of Care
}

\author{
Florian Roghmann ${ }^{a, b}$ Shyam Sukumar ${ }^{c}$ Praful Ravi ${ }^{c}$ Vincent Q. Trinh ${ }^{a}$ \\ Malek Meskawi ${ }^{a}$ Khurshid R. Ghanic Jesse D. Sammon ${ }^{c}$ Ariella A. Friedman ${ }^{c}$ \\ James O. Peabodyc Mani Menonc Joachim Noldus ${ }^{\mathrm{b}}$ Pierre I. Karakiewicz ${ }^{\mathrm{a}, \mathrm{d}}$ \\ Maxine Sun ${ }^{\mathrm{a}}$ Quoc-Dien Trinh ${ }^{\mathrm{a}, \mathrm{c}, \mathrm{d}}$ \\ ${ }^{a}$ Cancer Prognostics and Health Outcomes Unit, University of Montreal Health Center, Montreal, Canada; \\ ${ }^{\text {b}}$ Department of Urology, Ruhr University Bochum, Marienhospital, Herne, Germany; 'Vattikuti Urology Institute, \\ Henry Ford Health System, Detroit, Mich., USA; ${ }^{d}$ Department of Surgery, Division of Urology, Brigham and Women's \\ Hospital / Dana-Farber Cancer Institute, Harvard Medical School, Boston, Mass., USA
}

\section{Key Words}

Transitional cell carcinoma · Cystectomy · Postoperative complications Perioperative care

\begin{abstract}
Introduction: To examine national trends of radical cystectomy (RC) for urothelial carcinoma of urinary bladder in octogenarian patients and to assess the rates of adverse outcomes. Materials and Methods: Within the Nationwide Inpatient Sample (NIS), we focused on RCs performed between 1998 and 2007. Age was stratified as $<80$ versus $\geq 80$ years. Propensity-based matched analyses were used to account for treatment selection biases. Generalized linear regression analyses were fitted to predict adverse perioperative events according to age. Results: Of 12,274 RC patients, 1,605 were $\geq 80$ years $(13.1 \%)$. The $R C$ rates in octogenarians increased significantly from $9.9 \%$ in 1998 to $13.7 \%$ in 2007 . Most elderly patients were treated at low-/intermediate-volume hospitals (81.7\%) and nonacademic centers (60.6\%). After propensity score matching, the inpatient mortality rate was higher in octogenarians ( 4.6 vs. $2.6 \%, p<0.001$ ). In multivari-
\end{abstract}

able analyses, octogenarians were at increased risk of blood transfusions (OR: 1.30) and postoperative complications (OR: 1.22). Conclusions: Most octogenarians undergoing $R C$ are treated at low-/intermediate-volume hospitals and at nonacademic centers. The inpatient hospital mortality is about twice as high in these patients, and adverse perioperative outcomes are more frequent. Such patients may benefit from RC at high-volume and/or academic centers to maximally reduce adverse perioperative outcomes.

Copyright $\odot 2013$ S. Karger AG, Basel

\section{Introduction}

In 2010, urothelial carcinoma of the urinary bladder was diagnosed in 70,530 individuals in the United States and resulted in over 14,000 deaths [1]. The National Comprehensive Cancer Network (NCCN) guidelines [2]

Florian Roghmann and Shyam Sukumar contributed equally to this article.

\section{KARGER}

E-Mail karger@karger.com

www.karger.com/uin (c) 2013 S. Karger AG, Basel

0042-1138/13/0921-0027\$38.00/0
Florian Roghmann, MD

Cancer Prognostics and Health Outcomes Unit

264 blvd. Rene-Levesque E. suite 228

Montreal, QC, H2X 1P1 (Canada)

E-Mail f.roghmann@gmail.com 
recommend radical cystectomy (RC) for healthy patients with muscle-invasive disease. While RC has been shown to have excellent overall outcomes in the hands of expert surgeons [3], patients $\geq 80$ years of age have the highest cancer-specific mortality rates [4].

The impact of patient age on oncological outcomes and access to optimal therapies has attracted much attention [5-9]. For example, in patients undergoing radical prostatectomy for prostate cancer, elderly patients have higher rates of intraoperative complications, postoperative complications, and in-hospital mortality [10]. Several studies $[5,11,12]$ have assessed cancer control rates after RC in the elderly and several have found that urothelial carcinoma of the urinary bladder in the elderly are treated less aggressively $[9,13,14]$. However, far fewer studies $[7,15]$ have examined perioperative outcomes in octogenarians.

In this study, our aim was to examine national trends in adverse perioperative outcomes (intraoperative and postoperative complications, blood transfusions, transfer to a facility, and in-hospital mortality) in octogenarian patients treated with RC.

\section{Patients and Methods}

\section{Data Source}

We utilized the discharge records from the Nationwide Inpatient Sample (NIS). The NIS is a part of the Healthcare Cost and Utilization Project, sponsored by the Agency for Healthcare Research and Quality, and is recognized as the largest all-payer inpatient care database in the United States. As of 2007, the NIS contained outcomes from over 8 million hospital stays, thereby representing a $20 \%$ stratified sample of community hospitals, including academic and specialty hospitals within the United States [16].

All patients with a primary diagnosis of urothelial carcinoma of the urinary bladder (ICD-9-CM code 188) were identified within the NIS database. The cystectomy procedure code (ICD-9-CM 57.7) resulted in the identification of 12,274 patients who underwent RC between 1998 and 2007.

\section{Variable Definition}

Variables evaluated included patient age, year of surgery, race, Charlson Comorbidity Index (CCI), annual hospital volume (AHV), urban versus rural hospital location, academic institutional status, and hospital region (South vs. West vs. Northeast vs. Midwest). CCI was derived from ICD-9 codes in accordance with previously reported criteria [17] and stratified according to low (0-2) versus high $(\geq 3)$. AHV was defined according to the number of RCs performed at each participating institution during each study calendar year, and categorized as low (1-5 cases/year), intermediate (6-10 cases/year) and high ( $\geq 11$ cases/year). Transfer to a facility at discharge is defined as transfer to a short-term hospital or another type of facility (not including home health care). All other variables were extracted using a previously defined methodology [18].
Intraoperative, Postoperative Complications, and Blood

Transfusions during Hospitalization

The NIS records up to 15 diagnoses and procedures per inhospital admission. The presence of any complication was defined using ICD-9 diagnoses 2-15, the specifics of which have been demonstrated previously [18]. Patients were stratified by 0 versus 1 or greater complications during hospitalization. We used the same stratification to evaluate the rates of homologous blood transfusions.

\section{Statistical Analyses}

Frequencies and proportions were reported for categorical variables. Means, medians, and data ranges were reported for continuous variables. For continuous variables, normality was assessed using the Kolmogorov-Smirnov test [19], the Shapiro-Wilk test [20], and graphical plots. As continuous variables were not found to be normally distributed, univariate comparisons were made using the Mann-Whitney test. $\chi^{2}$ tests were used to compare the statistical significance of differences in proportions. To limit inherent baseline provider and patient differences between octogenarians and nonoctogenarians, a 3-to-1 propensity score-matched analysis was performed $[21,22]$. Propensity scores were computed by modeling logistic regression with the dependent variable as the odds of being $\geq 80$ years of age, and the independent variables as sex, race, ZIP code income, CCI, insurance status, urinary diversion, year of surgery, hospital location, and hospital volume. Subsequently, the covariate balance between the matched groups was examined.

Then, we used logistic regression models complemented by generalized estimating equations [23] to examine the effect of age on postoperative complication, homologous blood transfusion, and transfer to a facility. All models were further adjusted for race, CCI, AHV, insurance, hospital location (urban vs. rural), academic status, and hospital region. All statistical analyses were performed using the R statistical package system (R Foundation for Statistical Computing, Vienna, Austria), with a two-sided significance level set at $\mathrm{p}<0.05$.

\section{Results}

Between 1998 and 2007, 12,274 patients underwent $\mathrm{RC}$, of whom 1,605 were $\geq 80$ years $(13.1 \%)$. The rates of $\mathrm{RC}$ in octogenarians increased significantly during the study period from $9.9 \%$ in 1998 to $13.7 \%$ in 2007 ( $\mathrm{p}=$ 0.007; fig. 1). Table 1 shows the hospital and patient characteristics of the study cohort. The mean age of the octogenarian RC patients was 82.9 years (range: $80-95$ ). Most elderly patients were treated at low or intermediate AHV institutions $(81.7 \%)$ or at nonacademic centers $(60.6 \%)$. In univariable analyses (table 1), octogenarians had higher rates of intraoperative complications (3.4 vs. $2.3 \%, \mathrm{p}=$ 0.009 ), postoperative complications ( 35.9 vs. $29.4 \%$, p < 0.001 ), homologous blood transfusions (34.3 vs. $26.2 \%$, $\mathrm{p}<0.001$ ), in-hospital mortality (4.6 vs. $2.0 \%, \mathrm{p}<0.001$ ), total hospital charges (USD 67,537 vs. 60,121, p <0.001), and transfer to a facility (33.4 vs. $11.1 \%, \mathrm{p}<0.001)$. 
Table 1. Characteristics of 12,274 patients in the NIS who underwent RS in the USA between 1998 and 2007

\begin{tabular}{|c|c|c|c|c|}
\hline & Non-octogenarian & Octogenarian & Overall & $\mathrm{p}$ \\
\hline Number of patients & $10,669(86.9)$ & $1,605(13.1)$ & $12,274(100)$ & \\
\hline Year of surgery & & & & 0.002 \\
\hline $1998-2001$ & $3,801(35.6)$ & $498(31.0)$ & $4,299(35.0)$ & \\
\hline $2002-2004$ & $3,356(31.5)$ & $538(33.5)$ & $3,894(31.7)$ & \\
\hline 2005-2007 & $3,512(32.9)$ & $569(35.5)$ & $4,081(33.2)$ & \\
\hline Mean age (median), years & $66.3(68.0)$ & $82.9(82.0)$ & $68.5(70.0)$ & \\
\hline Range & $40-79$ & $80-95$ & $40-95$ & \\
\hline \multicolumn{5}{|l|}{ AHV } \\
\hline Low $(1-5)$ & $6,818(63.9)$ & $1,045(65.1)$ & $7,863(64.1)$ & 0.4 \\
\hline Intermediate $(6-10)$ & $1,752(16.4)$ & $267(16.6)$ & $2,019(16.4)$ & \\
\hline High $(\geq 11)$ & $2,099(19.7)$ & $293(18.3)$ & $2,392(19.5)$ & \\
\hline \multicolumn{5}{|l|}{ Race } \\
\hline \multicolumn{5}{|l|}{ Charlson score } \\
\hline 0 & $7,303(68.5)$ & $1,052(65.5)$ & $8,355(68.1)$ & $<0.001$ \\
\hline 1 & $2,448(22.9)$ & $367(22.9)$ & $2,815(22.9)$ & \\
\hline 2 & $516(4.8)$ & $89(5.5)$ & $605(4.9)$ & \\
\hline$\geq 3$ & $402(3.8)$ & $97(6.0)$ & $499(4.1)$ & \\
\hline Diversion type & & & & $<0.001$ \\
\hline Noncontinent & $9,258(86.8)$ & $1,528(95.2)$ & $10,786(87.9)$ & \\
\hline Continent & $799(7.5)$ & $13(0.8)$ & $812(6.6)$ & \\
\hline Unknown & $612(5.7)$ & $64(4.0)$ & $676(5.5)$ & \\
\hline Insurance status & & & & $<0.001$ \\
\hline Private & $3,699(34.7)$ & $105(6.5)$ & $3,804(31.0)$ & \\
\hline Medicaid & $424(4.0)$ & $11(0.7)$ & $435(3.5)$ & \\
\hline Midwest & $2,563(24.0)$ & $353(22.0)$ & $2,916(23.8)$ & \\
\hline South & $3,828(35.9)$ & $555(34.6)$ & $4,383(35.7)$ & \\
\hline West & $2,254(21.1)$ & $371(23.1)$ & $2,625(21.4)$ & \\
\hline \multicolumn{5}{|l|}{ Hospital location } \\
\hline Rural & $701(6.6)$ & $127(7.9)$ & $828(6.7)$ & 0.05 \\
\hline Urban & $9,968(93.4)$ & $1,478(92.1)$ & $11,446(93.3)$ & \\
\hline Mean length of stay (median), days & $11.1(9.0)$ & $12.5(10.0)$ & $11.3(9.0)$ & $<0.001$ \\
\hline IQR & $7-12$ & $8-14$ & 5 & \\
\hline Range & $0-161$ & $1-93$ & $0-161$ & \\
\hline Mean hospital charges (median), USD & $60,121(46,177)$ & $67,537(50,824)$ & $61,096(46,624)$ & $<0.001$ \\
\hline IQR & $32,095-67,984$ & $34,649-78,113$ & $32,408-69,167$ & \\
\hline Transfer to a facility & $536(33.4)$ & $1,182(11.1)$ & $1,718(14.0)$ & $<0.001$ \\
\hline Homologous blood transfusion & $2,795(26.2)$ & $551(34.3)$ & $3,346(27.3)$ & $<0.001$ \\
\hline Intraoperative complication & $250(2.3)$ & $55(3.4)$ & $305(2.5)$ & 0.009 \\
\hline Postoperative complication & $3,132(29.4)$ & $576(35.9)$ & $3,708(30.2)$ & $<0.001$ \\
\hline In-hospital mortality & $217(2.0)$ & $74(4.6)$ & $291(2.4)$ & $<0.001$ \\
\hline
\end{tabular}




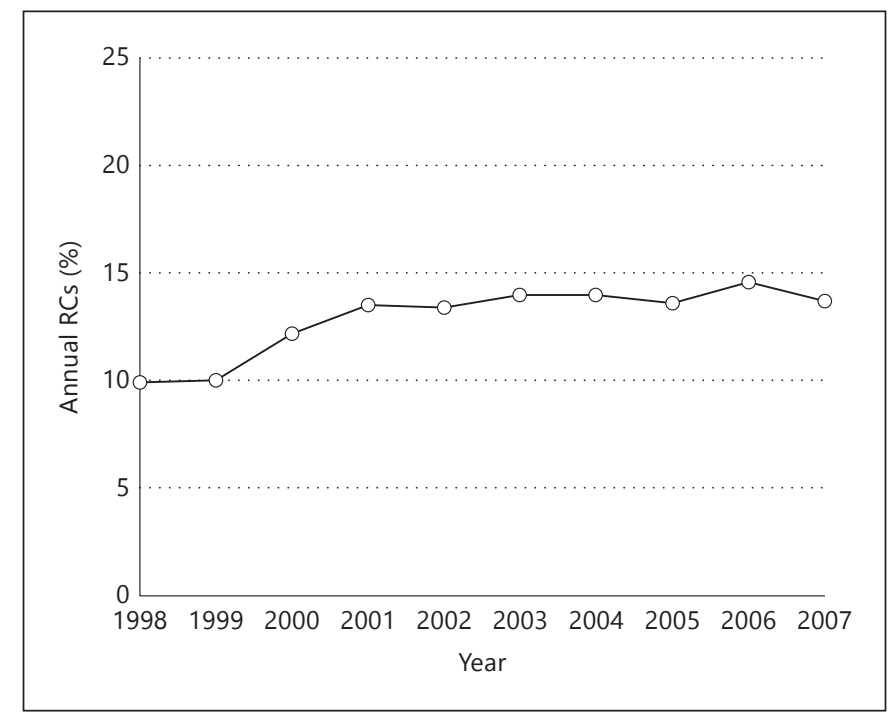

Fig. 1. Annual rate of RC in octogenarians within the NIS 19982007.

Following propensity-matched analysis, 4,815 nonoctogenarians were matched to 1,605 octogenarians. Standardized mean differences between the two groups in terms of patient and hospital characteristics were less than $10 \%$. The differences in demographic characteristics were not significant in the matched cohort, which reflected a high degree of similarity (table 2). The remainder of the analyses was conducted in the post-propensitymatched cohorts.

In the matched cohort, univariable analysis still showed a difference in intraoperative complications, but this difference failed to reach statistical significance (3.4 vs. $2.6 \%$, $\mathrm{p}=0.097)$. However, octogenarians still had higher rates of postoperative complications ( 35.9 vs. $31.5 \%, \mathrm{p}=0.001$ ), homologous blood transfusions (34.3 vs. $28.7 \%$, p < 0.001 ), in-hospital mortality (4.6 vs. $2.6 \%, \mathrm{p}<0.001$ ), total hospital charges (USD 67,537 vs. $64,509, \mathrm{p}<0.001$ ), and transfer to a facility ( 33.5 vs. $15.8 \%, \mathrm{p}<0.001$; table 3 ).

Table 4 shows the multivariable analyses in the matched cohort. Specifically, octogenarian patients were at higher risk of homologous blood transfusions (OR: 1.30, p < 0.001 ), postoperative complications (OR: $1.22, \mathrm{p}<0.001$ ), and transfer to a facility (OR: 2.81, p < 0.001).

Medicare patients have a higher risk of postoperative complications (OR: 1.37, $\mathrm{p}=0.007$ ) and transfer to a facility (OR: 1.94, $\mathrm{p}<0.001$ ). CCI was the strongest predictor of transfer to a facility (CCI $\geq 3$ vs. $0-2$, OR: $1.68, \mathrm{p}<0.001)$ and postoperative complications (CCI $\geq 3$ vs. 0 , OR: 1.43 , $p=0.002)$. Females were at a higher risk for blood transfu- sions (OR: $1.50, \mathrm{p}<0.001)$ and transfer to a facility (OR: $1.80, \mathrm{p}<0.001)$, but at a lower risk for postoperative complications (OR: $0.81, \mathrm{p}=0.001$ ). African-American patients were at a higher risk for blood transfusions (OR: 1.65, $p=0.004)$. Finally, patients treated at hospitals with a higher annual volume of cases were at a lower risk of transfer to a facility (per additional case OR: $0.98, \mathrm{p}=0.001$ ).

\section{Discussion}

$\mathrm{RC}$ has been shown to provide optimal long-term oncological control across all age groups $[3,24]$. In a landmark study, perioperative complications for patients of all ages undergoing RC were examined in the National Surgical Quality Improvement Program (NSQIP) database, which relies on Veterans Affairs Medical Centers (VAMC) nationwide. In this study, Hollenbeck et al. [25] reported that $30.5 \%$ of the patients had at least one complication and every 10-year increase in age increased the adjusted risk of having at least one complication by $30 \%$. However, the study was restricted to VAMC patients and the mean age of the studied cohort was 65.5 years, very similar to the younger cohort in our study (mean age: 66.3 years). In contrast, Donat et al. [7] in a single institutional series of octogenarian patients $(n=117)$ from a highvolume tertiary center of excellence (Memorial SloanKettering Cancer Center) revealed an equivalent ('nonsignificantly higher') rate of minor complications ( $55 \mathrm{vs.}$ $50 \%$ ), major complications (17 vs. $13 \%$ ), and 5-year cancer-specific mortality rates ( 26 vs. $25 \%$ ) relative to younger patients. Despite the equivalence of adverse outcomes at tertiary care centers, several population-based studies $[9,13,14]$ showed that RC is underutilized in octogenarians. This pattern may be due to concerns about higher perioperative morbidity and mortality in the elderly [26, 27]. In the current study, our objective was to test the hypothesis that perioperative RC outcomes may indeed be less favorable in octogenarian patients. While there are a number of small series on perioperative outcomes after $\mathrm{RC}$ in the elderly, there is a paucity of large-scale studies, especially with regard to national trends in contemporary perioperative RC outcomes $[8,28]$.

There were several noteworthy findings. First, direct comparisons of perioperative outcomes showed significant differences between octogenarians and their younger counterparts. Specifically, even after propensity score matching, the rates of homologous blood transfusions (34.2 vs. $28.7 \%, \mathrm{p}<0.001$ ), postoperative complications ( 35.9 vs. $31.5 \%, \mathrm{p}<0.001$ ), adverse discharge disposition 
Table 2. Propensity-matched (1:3) demographic characteristics of RC patients in the USA between 1998 and 2007 ( $\mathrm{n}=6,420)$

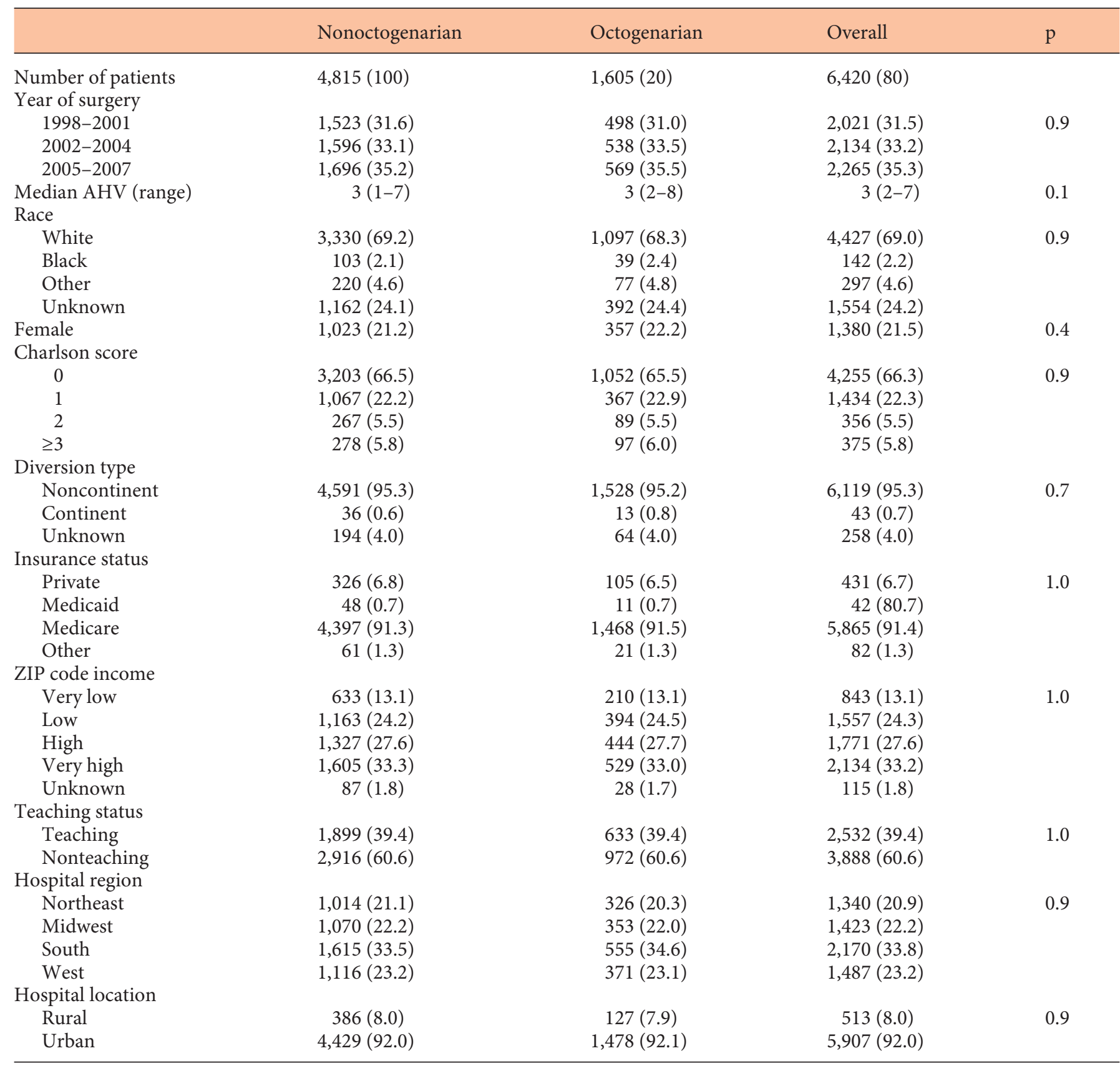

Values are n (\%) unless otherwise indicated. Multivariable predictions of various complications from several independent complication-specific regression models for octogenarians vs. nonoctogenarians undergoing RS.

(33.4 vs. $15.8 \%, \mathrm{p}<0.001)$, and in-hospital mortality $(4.6$ vs. $2.6 \%, \mathrm{p}<0.001)$ were significantly higher in octogenarians. Second, when specific subsets of postoperative complications were examined, we demonstrated that elderly patients were at higher risk for cardiac complica- tions ( 5.9 vs. $4.5 \%, \mathrm{p}<0.001)$. In multivariable analyses, octogenarian patients were at higher risk of homologous blood transfusions (OR: 1.30, $\mathrm{p}<0.001$ ), postoperative complications (OR: $1.22, \mathrm{p}<0.001$ ), and transfers to a facility (OR: 2.81, p < 0.001). 
Table 3. Independent predictors of complications in multivariable analyses of 12,274 patients who underwent RS

\begin{tabular}{|c|c|c|c|c|}
\hline Number of patients & $4,815(100)$ & $1,605(20)$ & $6,420(80)$ & \\
\hline Transfer to facility & $760(15.8)$ & $536(33.4)$ & $1,296(20.2)$ & $<0.001$ \\
\hline Homologous blood transfusion & $1,384(28.7)$ & $551(34.3)$ & $1,935(30.1)$ & $<0.001$ \\
\hline Intraoperative complication & $125(2.6)$ & $55(3.4)$ & $180(2.8)$ & 0.097 \\
\hline Postoperative complication & $1,517(31.5)$ & $576(35.9)$ & $2,093(32.6)$ & 0.001 \\
\hline Cardiac complication & $218(4.5)$ & $94(5.9)$ & $312(4.9)$ & 0.037 \\
\hline Respiratory complication & $159(3.3)$ & $70(4.4)$ & $229(3.6)$ & 0.052 \\
\hline Digestive complication & $828(17.2)$ & $309(19.3)$ & $1,137(17.7)$ & 0.064 \\
\hline Urinary complication & $161(3.3)$ & $52(3.2)$ & $213(3.3)$ & 0.873 \\
\hline Wound complication & $197(4.1)$ & $64(4.0)$ & $261(4.1)$ & 0.884 \\
\hline Hematoma complication & $143(3.0)$ & $57(3.6)$ & $200(3.1)$ & 0.246 \\
\hline Seroma complication & $20(0.4)$ & $12(0.7)$ & $32(0.5)$ & 0.105 \\
\hline Mean hospital charges (median), USD & $64,509(48,025)$ & $67,537(50,824)$ & $65,272(48,702)$ & \\
\hline IQR & $33,091-73,113$ & $34,649-78,113$ & $33,407-74,356$ & 0.011 \\
\hline
\end{tabular}

Values are $\mathrm{n}(\%)$ unless otherwise indicated. Treatment characteristics and perioperative outcomes of RC patients in the USA between 1998 and 2007 [propensity matched (1:3), $\mathrm{n}=6,420$ ].

Taken together, these findings convincingly show that the adverse perioperative outcomes were more frequent in the elderly. This risk elevation needs to be communicated to elderly RC candidates. However, the increased risks are not prohibitive. Therefore, $\mathrm{RC}$ represents a valid treatment option for octogenarians. Importantly, detailed cardiopulmonary preoperative evaluation is warranted to optimize their functional status and maximally reduce cardiopulmonary complications.

Third, we report higher rates of transfer to a facility for elderly patients undergoing RC. We have previously reported the discharge patterns for patients of all ages undergoing RC and discussed the importance of hospital volume, insurance status, and academic status of the treating institution in predicting transfer to a facility [18]. In the current study, it is noteworthy that octogenarians had a 2.8 -fold higher risk for nonroutine transfer to a facility for further care following discharge, even after controlling for multiple patient and sociodemographic factors (including the above-mentioned factors that were significant in previous analyses). This consideration is important in early discharge planning and in RC cost considerations.

While our findings demonstrate that $\mathrm{RC}$ rates in octogenarians increased between 1998 and 2007, most RCs were performed at low-to-intermediate AHV centers. This finding is significant because, in our analysis, patients treated at high AHV hospitals were at a significantly lower risk for transfer to a facility at discharge. In an exhaustive systematic review, Goossens-Laan et al. [29] confirmed the inverse relationship between surgical volume and postoperative mortality after RC. Similarly, Hollenbeck et al. [30] reported that for every 111 RCs regionalized to higher volume centers annually, one life would be saved. Our findings indicate that octogenarians represent an ideal group for volume-based referral to more specialized centers of care.

From a practical perspective, our findings indicate that elderly age is a significant risk factor and negative prognosticator for multiple adverse perioperative endpoints. This is especially true for patients with high CCI as well as patients with Medicaid insurance. It is clear that the majority of RCs in the elderly were performed in low-tointermediate volume hospitals and nonacademic centers. One reason for this may include the reluctance of elderly patients to seek care further away from their home environment with possible implications for support from network of family and friends. However, from a health policy perspective, our results provide a stronger argument for regionalization of care for this particularly vulnerable 
Table 4. Propensity-matched (1:3) demographic characteristics of RC patients in the USA between 1998 and 2007 ( $\mathrm{n}=6,420)$

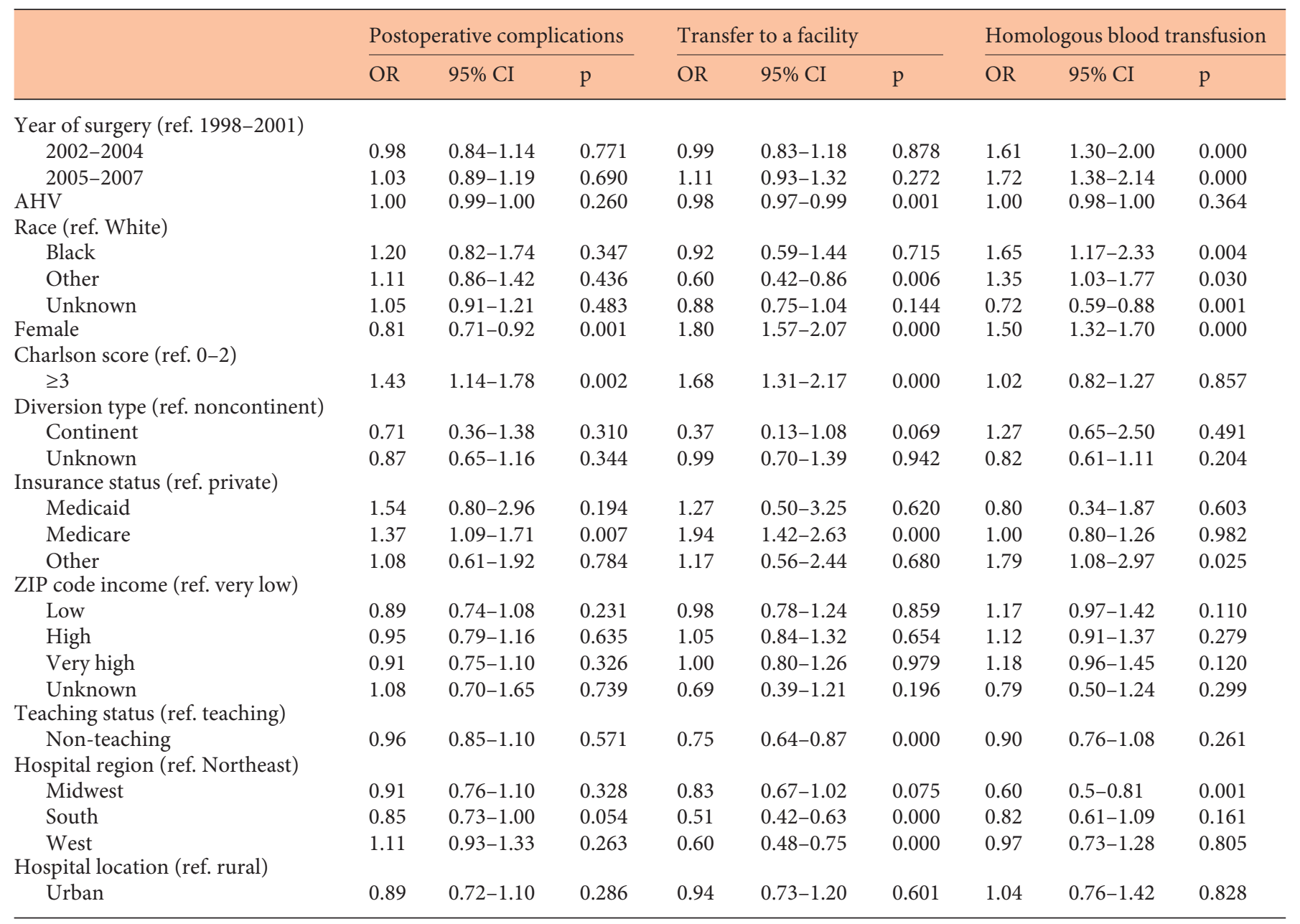

subset of patients. To the best of our knowledge, other studies have not specifically focused on national perioperative outcomes for octogenarians undergoing RC and risk-quantification for specific complications.

Our study is not without limitations. Lack of data pertaining to individual surgical volume represents a drawback. Ideally, this variable would have been included in the analyses. It is important to note that this limitation equally applies to octogenarian and nonoctogenarian patients. Consequently, it is unlikely that it affected the results of our study. Other variables that may have influenced the results are also not available. For example, patient factors (disease characteristics, personal preferences, education) and socioeconomic variables could not be examined in multivariable modeling. We report on perioperative outcomes after RC in a US cohort, but it remains uncertain if our findings are applicable to other populations.

\section{Conclusions}

Octogenarians are at increased risk of adverse perioperative outcomes after RC, namely blood transfusions, postoperative complications, adverse discharge disposition, and in-hospital mortality. Surgeons should pay special attention to the prevention and expectant management of cardiopulmonary complications. From a health policy perspective, these patients are at higher risk of adverse outcomes and would benefit from treatment at referral centers where better outcomes have been reported.

\section{Disclosure Statement}

Nothing to disclose. 


\section{References}

1 Jemal A, Siegel R, Xu J, Ward E: Cancer statistics, 2010. CA Cancer J Clin 2010;60:277300.

-2 Montie JE, Clark PE, Eisenberger MA, El-Galley R, Greenberg RE, Herr HW, Hudes GR, Kuban DA, Kuzel TM, Lange PH, Lele SM, Michalski J, Patterson A, Pohar KS, Richie JP, Sexton WJ, Shipley WU, Small EJ, Trump DL, Walther PJ, Wilson TG: Bladder cancer. J Natl Compr Canc Netw 2009;7:8-39.

$>3$ Stein JP, Lieskovsky G, Cote R, Groshen S, Feng AC, Boyd S, Skinner E, Bochner B, Thangathurai D, Mikhail M, Raghavan D, Skinner DG: Radical cystectomy in the treatment of invasive bladder cancer: long-term results in 1,054 patients. J Clin Oncol 2001;19: 666-675.

4 Lughezzani G, Sun M, Shariat SF, Budaus L, Thuret R, Jeldres C, Liberman D, Montorsi F, Perrotte P, Karakiewicz PI: A populationbased competing-risks analysis of the survival of patients treated with radical cystectomy for bladder cancer. Cancer 2011;117:103109.

$>5$ Hollenbeck BK, Miller DC, Taub D, Dunn RL, Underwood W 3rd, Montie JE, Wei JT: Aggressive treatment for bladder cancer is associated with improved overall survival among patients 80 years old or older. Urology 2004; 64:292-297.

6 Clark PE, Stein JP, Groshen SG, Cai J, Miranda G, Lieskovsky G, Skinner DG: Radical cystectomy in the elderly: comparison of clincal outcomes between younger and older patients. Cancer 2005;104:36-43.

7 Donat SM, Siegrist T, Cronin A, Savage C, Milowsky MI, Herr HW: Radical cystectomy in octogenarians - does morbidity outweigh the potential survival benefits? J Urol 2010; 183:2171-2177.

$>8$ Froehner M, Brausi MA, Herr HW, Muto G, Studer UE: Complications following radical cystectomy for bladder cancer in the elderly. Eur Urol 2009;56:443-454.

$>9$ Konety BR, Joslyn SA: Factors influencing aggressive therapy for bladder cancer: an analysis of data from the SEER program. J Urol 2003; 170:1765-1771.

10 Trinh QD, Schmitges J, Sun M, Shariat SF, Sukumar S, Tian Z, Bianchi M, Sammon J, Perrotte P, Rogers CG, Graefen M, Peabody JO, Menon M, Karakiewicz PI: Open radical prostatectomy in the elderly: a case for concern? BJU Int 2012;109:1335-1340.
11 Clark PE, Stein JP, Groshen SG, Cai J, Miranda G, Lieskovsky G, Skinner DG: Radical cystectomy in the elderly: comparison of survival between younger and older patients. Cancer 2005; 103:546-552.

12 Nielsen ME, Shariat SF, Karakiewicz PI, Lotan Y, Rogers CG, Amiel GE, Bastian PJ, Vazina A, Gupta A, Lerner SP, Sagalowsky AI, Schoenberg MP, Palapattu GS: Advanced age is associated with poorer bladder cancer-specific survival in patients treated with radical cystectomy. Eur Urol 2007;51:699-706, discussion 706-708.

13 Schrag D, Mitra N, Xu F, Rabbani F, Bach PB, Herr H, Begg CB: Cystectomy for muscle-invasive bladder cancer: patterns and outcomes of care in the Medicare population. Urology 2005;65:1118-1125.

14 Prout GR Jr, Wesley MN, Yancik R, Ries LA, Havlik RJ, Edwards BK: Age and comorbidity impact surgical therapy in older bladder carcinoma patients: a population-based study. Cancer 2005; 104:1638-1647.

15 Novotny V, Hakenberg OW, Froehner M, Zastrow S, Leike S, Koch R, Wirth MP: Systematic assessment of complications and outcome of radical cystectomy undertaken with curative intent in patients with comorbidity and over 75 years of age. Urol Int 2013;90: 195-201.

16 HCUP Nationwide Inpatient Sample (NIS). Healthcare cost and utilization project (HCUP) 1998-2007. Agency for Healthcare Research and Quality, Rockville, Md. http:// www.hcup-us.ahrq.gov/nisoverview.jsp.

17 Deyo RA, Cherkin DC, Ciol MA: Adapting a clinical comorbidity index for use with ICD9-CM administrative databases. J Clin Epidemiol 1992;45:613-619.

18 Bianchi M, Trinh QD, Sun M, Sammon J, Schmitges J, Shariat SF, Sukumar S, Ghani KR, Jeldres C, Perrotte P, Rogers CG, Briganti A, Peabody JO, Montorsi F, Menon M, Karakiewicz PI: Discharge patterns after radical cystectomy: contemporary trends in the United States. J Urol 2012;187:1206-1209.

19 Darling DA: The Kolmogorov-Smirnov, Cramer-V Mises tests. Ann Math Stat 1957;28: 823-838.

20 Shapiro SS, Wilk MB: An analysis of variance test for normality (complete samples). Biometrika 1965;52:591-611.
21 D'Agostino RB Jr: Propensity score methods for bias reduction in the comparison of a treatment to a non-randomized control group. Stat Med 1998;17:2265-2281.

-22 Stukel TA, Fisher E, Wennberg DE, Alter DA, Gottlieb DJ, Vermeulen MJ: Analysis of observational studies in the presence of treatment selection bias: effects of invasive cardiac management on AMI survival using propensity score and instrumental variable methods. JAMA 2007;297:278-285.

23 Panageas KS, Schrag D, Riedel E, Bach PB, Begg CB: The effect of clustering of outcomes on the association of procedure volume and surgical outcomes. Ann Intern Med 2003;139: 658-665.

-24 Aboumarzouk OM, Drewa T, Olejniczak P, Chlosta PL: Laparoscopic versus open radical cystectomy for muscle-invasive bladder cancer: a single institute comparative analysis. Urol Int 2013;91:109-112.

25 Hollenbeck BK, Miller DC, Taub D, Dunn RL, Khuri SF, Henderson WG, Montie JE, Underwood W 3rd, Wei JT: Identifying risk factors for potentially avoidable complications following radical cystectomy. J Urol 2005;174: 1231-1237, discussion 1237.

26 Gore JL, Litwin MS, Lai J, Yano EM, Madison R, Setodji C, Adams JL, Saigal CS: Use of radical cystectomy for patients with invasive bladder cancer. J Natl Cancer Inst 2010;102: 802-811.

27 Froehner M, Scholz A, Koch R, Hakenberg OW, Baretton GB, Wirth MP: Competing mortality contributes to excess mortality in patients with poor-risk lymph node-positive prostate cancer treated with radical prostatectomy. Urol Int 2012;89:148-154.

28 Roghmann F, Noldus J, von Bodman C, Holz A, Brock M, Palisaar J: Cystectomy in elderly patients: analysis of complications using the Clavien-Dindo classification (in German). Urologe A 2012;51:1386-1392.

29 Goossens-Laan CA, Gooiker GA, van Gijn W, Post PN, Bosch JL, Kil PJ, Wouters MW: A systematic review and meta-analysis of the relationship between hospital/surgeon volume and outcome for radical cystectomy: an update for the ongoing debate. Eur Urol 2011; 59:775-783.

30 Hollenbeck BK, Dunn RL, Miller DC, Daignault S, Taub DA, Wei JT: Volume-based referral for cancer surgery: informing the debate. J Clin Oncol 2007;25:91-96. 